\title{
Appropriate Use Criteria for Imaging Evaluation of Biochemical Recurrence of Prostate Cancer After Definitive Primary Treatment
}

\author{
Hossein Jadvar ${ }^{1}$, Leslie K. Ballas ${ }^{2}$, Peter L. Choyke ${ }^{3}$, Stefano Fanti ${ }^{4}$, James L. Gulley ${ }^{5}$, Ken Herrmann ${ }^{4}$, Thomas A. Hope ${ }^{1}$, \\ Alan K. Klitzke ${ }^{6}$, Jorge D. Oldan ${ }^{1,3}$, Martin G. Pomper ${ }^{7}$, Steven P. Rowe ${ }^{1}$, Rathan M. Subramaniam ${ }^{6,8}$, Samir S. Taneja ${ }^{9}$, \\ Herbert Alberto Vargas ${ }^{3}$, and Sukhjeet Ahuja ${ }^{1}$ \\ ${ }^{1}$ Society of Nuclear Medicine and Molecular Imaging, Reston, Virginia; ${ }^{2}$ American Society for Radiation Oncology, Arlington, \\ Virginia; ${ }^{3}$ American Society of Clinical Oncology, Alexandria, Virginia; ${ }^{4}$ European Association of Nuclear Medicine, Vienna, Austria; \\ ${ }^{5}$ American College of Physicians, Philadelphia, Pennsylvania; ${ }^{6}$ American College of Nuclear Medicine, Reston, Virginia; ${ }^{7}$ World \\ Molecular Imaging Society, Culver City, California; ${ }^{8}$ American College of Radiology, Reston, Virginia; and ${ }^{9}$ American Urological \\ Association, Linthicum Heights, Maryland
}

\section{EXECUTIVE SUMMARY}

Imaging is often used to evaluate men with biochemical recurrence (BCR) of prostate cancer after definitive primary treatment (radical prostatectomy $[\mathrm{RP}]$ or radiotherapy $[\mathrm{RT}])$. The goal of imaging is to identify the source of elevated or rising serum prostate-specific antigen (PSA) levels because subsequent management depends on disease location and extent. Salvage therapy (with surgery or radiation) may be considered for select cases with BCR to provide additional potential opportunity for cure. The salvage treatment strategy may be extended to regional adenopathy. Patients with limited distant metastases on imaging, referred to as oligometastatic disease ( $\leq 5$ demonstrable lesions), may be candidates for close observation, systemic hormonal therapy, or metastases-directed therapies with or without local therapy, depending on sites of recurrence. Patients with metastatic disease are typically treated with systemic therapy.

The purpose of this document is to describe the appropriate use of imaging in the diagnostic evaluation of patients with BCR after definitive primary treatment. The imaging modalities that were considered included CT, bone scan, and the U.S. Food and Drug Administration (FDA)-approved PET radiotracers that track malignancy-induced lipogenesis $\left({ }^{11} \mathrm{C}\right.$-choline $)$ and amino acid metabolism ( ${ }^{18} \mathrm{~F}$-fluciclovine). The prostate-specific membrane antigen (PSMA)-targeted monoclonal antibody, ${ }^{111}$ In-capromab pendetide, is also included for historical perspective because it is neither available nor used clinically. The new class of PSMA-targeted PET radiotracers have generated considerable interest and are discussed briefly, although these agents are currently not approved for routine clinical use in the United States. Moreover, whole-body MRI (WB-MRI), with or without diffusion-weighted imaging, is excluded. Although WB-MRI may have utility in this clinical setting, particularly for the detection of bone metastases, the variability in availability, accessibility, quality, and standardization, as well as the fact that there are no currently established procedural

Received Dec. 12, 2019; revision accepted Dec. 12, 2019.

For correspondence or reprints contact: Sukhjeet Ahuja, Society of Nuclear Medicine and Molecular Imaging, 1850 Samuel Morse Dr., Reston, VA 20190. E-mail: sahuja@snmmi.org

COPYRIGHT (C) 2020 by the Society of Nuclear Medicine and Molecular Imaging. DOI: 10.2967/jnumed.119.240929 terminology codes for reimbursement, has hindered its clinical adoption $(1,2)$.

Representatives from the Society of Nuclear Medicine and Molecular Imaging (SNMMI), the European Association of Nuclear Medicine (EANM), the American Society of Clinical Oncology (ASCO), the American College of Nuclear Medicine (ACNM), the American Society for Radiation Oncology (ASTRO), the American Urological Association (AUA), the American College of Physicians (ACP), the American College of Radiology (ACR), and the World Molecular Imaging Society (WMIS) assembled under the auspices of an autonomous workgroup to develop the following appropriate use criteria (AUC). This process was performed in accordance with the Protecting Access to Medicare Act of 2014 (3). This legislation requires that all referring physicians consult AUC by using a clinical decision support mechanism before ordering advanced diagnostic imaging services. These services include diagnostic MRI, CT, and nuclear medicine procedures such as PET, among other services specified by the Secretary of Health and Human Services in consultation with physician specialty organizations and other stakeholders. The AUC herein are intended to aid referring medical practitioners in the appropriate use of imaging for the diagnostic evaluation of patients with BCR of prostate cancer after definitive primary treatment.

Prostate cancer is the second most commonly diagnosed cancer worldwide ( $13.5 \%$ of cancer diagnoses in men; $1,276,106$ cases in 2018) and the fifth most common cause of cancer-related mortality among males $(6.7 \% ; 358,989$ deaths in 2018) (4). In the United States, prostate cancer is the most commonly diagnosed nonskin cancer in men (a projected 19\% of all new cases of cancer; 164,690 cases in 2018) and the second most common cause of cancer-related mortality (a projected 29,430 deaths in 2018) (5). Despite local definitive therapy, up to $40 \%$ of patients will develop recurrent disease (6). Most of these patients will have BCR with no evidence of metastasis on the basis of widely used standard imaging techniques (contrast-enhanced abdomen and pelvis CT, WB ${ }^{99 m}$ Tc-based bone scan, or pelvis multiparametric MRI), and the disease will manifest only with elevated serum PSA levels.

The definition of BCR (also referred to as PSA relapse) depends on the type of prior definitive therapy. In patients who have undergone RP, the AUA defines BCR when the serum PSA level 
is $\geq 0.2 \mathrm{ng} / \mathrm{mL}$, measured 6-13 wk after surgery, and confirmed by a second determination of a PSA level of $>0.2 \mathrm{ng} / \mathrm{mL}$ (7). In patients treated with RT, the ASTRO Phoenix Criteria defines $\mathrm{BCR}$ as a rise in PSA level of $2 \mathrm{ng} / \mathrm{mL}$ or more above the nadir regardless of androgen deprivation therapy (ADT) (8).

The significance of biochemically recurrent disease varies considerably according to individual risk factors. One clinically important prognostic variable is PSA doubling time. For instance, prostate cancer-specific survival is approximately $90 \%$ in patients with a PSA doubling time of $\geq 15$ mo (highest quartile), whereas it is about $20 \%$ for patients with a PSA doubling time of $<3$ mo (lowest quartile) (9). In part because of this wide variability in disease aggressiveness, coupled with competing causes of mortality and the typically long time to documented metastatic disease by standard imaging (median metastasis-free survival is $10 \mathrm{y}$ in patients with BCR and no treatment), there is no defined standard management for this patient population (10). The development of metastasis in a patient signals that a change in treatment approach is warranted. Since the 1940s, the foundation of treatment for metastatic prostate cancer has been testosterone-lowering therapy. It is likely that the use of more sensitive imaging techniques will identify patients earlier who are at higher risk of developing overt metastases identified by more commonly used techniques. In some scenarios, earlier intervention in the disease process may result in improved outcomes for patients, as has been seen with postoperative RT (11).

RT after a prostatectomy is commonly used to eradicate microscopic residual disease in the prostate bed, thereby reducing the risk of recurrence. Defining who needs postoperative RT is most often based on surgical pathology and postoperative PSA because standard imaging does not have sufficient sensitivity to identify early recurrences in the PSA range where salvage treatment is more likely to be curative. There is growing evidence that genomic biomarkers (e.g., Decipher, GenomeDx Biosciences, San Diego, CA) can have utility in this clinical setting, although it remains unclear as to how this information affects imaging choice $(12,13)$. In the adjuvant setting, pathology (pT3a/b or surgical margins positive for disease) currently drives the addition of RT. In the salvage setting, when men have persistently detectable PSA (PSA persistence) or a delayed rise in PSA level ( $\geq 0.2 \mathrm{ng} / \mathrm{mL})$, conventional imaging does not have sufficient sensitivity to identify early recurrences. The ability to detect residual or recurrent disease within the pelvis can affect RT dose and target. In the absence of molecular imaging, the question of whether to include pelvic lymph nodes in the RT field in patients with pathologic node-negative disease is a question that has been studied by the Radiation Therapy Oncology Group (RTOG) 0534 trial and is awaiting final results. The first report from RTOG 0534 (3-arm randomized trial) shows gains in freedom from progression with the addition of short-term (4-6 mo) ADT to prostate bed radiation and further gains with the inclusion of pelvic lymph node RT and short-term ADT over a PSA level of $0.34 \mathrm{ng} / \mathrm{mL}$ (14). With the ability to visualize prostate cancer cells, molecular imaging can help define RT treatment fields. Similarly, molecular imaging can identify patients who have early metastatic disease and could avoid RT to the prostate fossa. The use of molecular imaging to identify oligometastatic prostate cancer has allowed for additional treatment strategies in patient care (15). Studies show a benefit (e.g., biochemical progression-free survival, distant progressionfree survival) to metastasis-directed stereotactic body RT in the setting of oligometastatic prostate cancer (16-18). Molecular imaging can enhance the postoperative treatment algorithm for prostate cancer patients by identifying targets for RT.

This document is the product of an extensive literature search in combination with expert opinion. Its intent is to provide upto-date information and recommendations for AUC for approved (in the United States) imaging technologies in the setting of BCR of prostate cancer after definitive treatment. We also discuss the outlook for upcoming imaging technologies that are anticipated to be approved in the United States relatively soon.

\section{METHODOLOGY}

\section{Expert Workgroup Selection}

The experts of this AUC workgroup were convened by the SNMMI to represent a multidisciplinary panel of health-care providers with substantive knowledge in the use of imaging evaluation of BCR of prostate cancer after definitive primary treatment. In addition to SNMMI members, representatives from ASCO, ASTRO, EANM, ACP, ACNM, AUA, ENETS, WMIS, and ACR were included in the workgroup. Fourteen physician members were ultimately selected to participate and contribute to the AUC. A complete list of workgroup participants and external reviewers can be found in Appendix A. Appendix B provides the disclosures and conflict of interest (COI) statements, and Appendix $\mathrm{C}$ describes the solicitation of public commentary.

\section{AUC Development}

The process for AUC development was modeled after the RAND/UCLA Appropriateness Method for AUC development (19). The process included the identification of a list of relevant clinical scenarios in which nuclear medicine can be used for imaging evaluation of BCR of prostate cancer after definitive primary treatment; a systematic review of evidence related to these clinical scenarios; and a systematic synthesis of available evidence, followed by the development of AUC for each of the various clinical scenarios by using a modified Delphi process. In addition, in this process we strove to adhere to the Institute of Medicine's standards for developing trustworthy clinical guidance $(20,21)$. The final document was drafted on the basis of group ratings and discussions.

\section{Scope and Development of Clinical Scenarios}

To begin this process, the workgroup discussed various potential clinical indications and applicable scenarios for the evaluation of BCR of prostate cancer after definitive primary therapy. For all indications, the relevant populations were patients with prostate cancer. The workgroup identified 2 clinical categories with 12 scenarios for this document. The categories are intended to be as representative of the relevant patient population as possible for the development of AUC. The resulting AUC are based on evidence and expert opinion regarding diagnostic accuracy and effects on clinical outcomes and clinical decision making as applied to each indication. Other factors affecting the AUC recommendations were potential harm-including long-term harm that may be difficult to capture—costs, availability, and patient preferences.

\section{Systematic Review}

ASCO conducted a systematic review to develop a comprehensive clinical practice guideline for optimum imaging strategies for advanced prostate cancer, and the same systematic review was 
used by the AUC workgroup. The workgroup selected the following key questions to guide the review:

1. What is the goal of imaging in advanced prostate cancer?

2. What imaging techniques are available for imaging advanced prostate cancer?

3. What are the unmet needs and potential impact of imaging according to different advanced prostate cancer disease states?

4. When and what type of imaging is appropriate in each scenario?

The inclusion and exclusion criteria for papers for this review were based on the study parameters established by the workgroup, using the PICOTS (population, intervention, comparisons, outcomes, timing, and setting) approach. A protocol for each systematic review defined parameters for a targeted literature search. Additional parameters included relevant study designs, literature sources, types of reports, and prespecified inclusion and exclusion criteria for the literature identified. The protocol for this guideline was reviewed and approved by the ASCO Clinical Practice Guidelines Committee's Genitourinary Cancer Guideline Advisory Group.

PubMed and the Cochrane Collaboration Library electronic databases (with or without meeting abstracts) were searched for evidence that reported on outcomes of interest.

\section{Data Extraction}

Literature search results were reviewed and deemed appropriate for full text review by one ASCO staff reviewer in consultation with the expert panel cochairs (Edouard J Trabulsi, MD, Sidney Kimmel Medical College at Thomas Jefferson University, Philadelphia, PA, and Alberto Vargas, MD, Memorial Sloan Kettering Cancer Center, New York, NY). Data were extracted by 1 staff reviewer and subsequently checked for accuracy through an audit of the data by another ASCO staff member. Disagreements were resolved through discussion and consultation with the cochairs if necessary. Discrepancies were resolved through a consensus process.

\section{Study Quality Assessment}

Study quality was formally assessed for the studies identified. Design aspects related to the individual study quality were assessed by 1 reviewer and included factors such as blinding, allocation concealment, placebo control, intention to treat, funding sources, etc. The risk of bias was assessed as "low," "intermediate," or "high" for most of the identified evidence.

Database searches resulted in 6,378 potentially relevant abstracts. After dual review of abstracts and titles, 66 articles were selected for full-text dual review. Of these, 35 studies were determined to meet inclusion criteria and were included in this review, including 17 systematic reviews and 18 primary research papers.

\section{Rating and Scoring}

In developing these criteria, the workgroup members used the following definition of appropriateness to guide their considerations and group discussions: "The concept of appropriateness, as applied to health care, balances risk and benefit of a treatment, test, or procedure in the context of available resources for an individual patient with specific characteristics." At the beginning of the process, workgroup members convened via webinars to develop the initial clinical indications. On evaluating the evidence summary of the systematic literature review, the workgroup further refined its draft clinical indications to ensure their accuracy and to facilitate consistent interpretation when scoring each indication for appropriateness. Using the evidence summary, workgroup members were first asked individually to assess the appropriateness and to provide a score for each of the identified indications. Workgroup members then convened in a group setting for several successive webinars to discuss each indication and associated scores from the first round of individual scoring. After deliberate discussion, a consensus score was determined and then assigned to the associated appropriate use indication. For this scoring round, the expert panel was encouraged to include their clinical expertise in addition to the available evidence in determining the final scores. All members contributed to the final discussion, and no one was forced into consensus. After the rating process was completed, the final appropriate use ratings were summarized in a format similar to that outlined by the RAND/ UCLA Appropriateness Method.

The workgroup scored each indication as "appropriate," "may be appropriate," or "rarely appropriate" on a scale from 1 to 9. Scores 7-9 indicate that the use of the procedure is appropriate for the specific clinical indication and is generally considered acceptable. Scores 4-6 indicate that the use of the procedure may be appropriate for the specific indication. This implies that more research is needed to classify the indication definitively. Scores 1-3 indicate that the use of the procedure is rarely appropriate for the specific indication and is generally not considered acceptable.

As stated by other societies that develop AUC, the division of these scores into 3 general levels of appropriateness is partially arbitrary, and the numeric designations should be viewed as a continuum. In addition, if there was a difference in clinical opinion for an indication such that workgroup members could not agree on a common score, that indication was given a "may be appropriate" rating to indicate a lack of agreement on appropriateness on the basis of available literature and the members' collective clinical opinion, indicating the need for additional research.

\section{Clinical Categories and AUC Scores}

Category 1. BCR after prior definitive treatment with RP or RT-initial imaging investigation

Category 2. BCR after prior definitive treatment with RP or RT-negative or equivocal results on initial standard imaging

Table 1 presents the clinical category and final AUC scores for the use of imaging in the evaluation of BCR of prostate cancer after definitive primary treatment with RP or RT.

Table 2 presents the clinical category and final AUC scores for the use of imaging in the evaluation of BCR of prostate cancer after definitive primary treatment with RP or RT, with negative or equivocal results on standard imaging.

Category 1, Scenario 1: CT of the Abdomen and Pelvis with Intravenous Contrast (Score 8-Appropriate). An abdominal and pelvis CT in prostate cancer treatment follow-up is used to focus on the assessment of metastatic disease in the lymph nodes, bone, and visceral organs. In the evaluation of nodal disease, CT relies on nodal size to detect tumors. Using a short-axis diameter of 1.0 $\mathrm{cm}$ as a cut point, studies have reported sensitivities of between $27 \%$ and $75 \%$ with specificities of between $66 \%$ and $100 \%$ (22). However, the sensitivity of abdominopelvic CT for the detection of low-volume recurrent disease is limited, particularly when PSA levels are low. Studies have shown CT results to be positive in only $11 \%-14 \%$ of men with biochemical relapse after RP (23). 
TABLE 1

CATEGORY 1: Clinical Scenarios for BCR After Prior Definitive Treatment with RP or RT-Initial Imaging Investigation

\begin{tabular}{|c|c|c|c|}
\hline Scenario no. & Description & Appropriateness & Score \\
\hline 1 & CT abdomen and pelvis with intravenous contrast & Appropriate & 8 \\
\hline 2 & CT chest with intravenous contrast & Rarely appropriate & 2 \\
\hline 3 & Bone scan $\left({ }^{99 m} \mathrm{Tc},{ }^{18} \mathrm{~F}-\mathrm{NaF}\right)$ & Appropriate & 8 \\
\hline 4 & Pelvis MRI with and without intravenous contrast & Appropriate & 8 \\
\hline 5 & ${ }^{18} \mathrm{~F}-\mathrm{FDG}$ PET/CT (skull base to midthigh) & Rarely appropriate & 2 \\
\hline 6 & ${ }^{11} \mathrm{C}$-choline PET/CT (skull base to midthigh) & May be appropriate & 6 \\
\hline 7 & ${ }^{18} \mathrm{~F}$-fluciclovine PET/CT (skull base to midthigh) & May be appropriate & 6 \\
\hline 8 & ${ }^{111}$ In-capromab pendetide & Rarely appropriate & 1 \\
\hline
\end{tabular}

The mean PSA value associated with positive results for disease in a CT examination was $12.4 \mathrm{ng} / \mathrm{mL}$, and the mean PSA velocity was $30.6 \mathrm{ng} / \mathrm{mL} / \mathrm{y}(24)$. The usual pattern of vertical nodal spread beginning in the pelvis can be absent in nearly $75 \%$ of patients with disease recurrence after treatment (25). In these patients, most of whom have undergone previous pelvic lymph node dissection at the time of RP, only retroperitoneal adenopathy is commonly detected by CT. In addition, CT is useful to detect advanced disease in bone and visceral metastases and in RT treatment planning to define the prostate bed and locoregional and distant metastatic target volumes. Bone lesions from prostate cancer are often seen as sclerotic lesions, although there are numerous other benign causes for dense bone lesions. A bone scan is superior to CT in the diagnosis and follow-up of bone metastases, as it provides functional information about a bone lesion. In summary, despite the recognized limitations of an abdominopelvic CT, it is readily available at relatively low cost and has traditionally been considered as standard imaging in this clinical setting, which prompted the panel to recommend an appropriateness score of 8 (appropriate).

Category 1, Scenario 2: CT of the Chest With Intravenous Contrast (Score 2 - Rarely Appropriate). Lung metastasis from prostate cancer is relatively uncommon. In an autopsy series, the relative ratio frequency of lung involvement was $14.2 \%-19.8 \%$ (26). Moreover, most lung metastases appear later in the disease and not early in the recurrence setting. Therefore, the panel recommended that CT of the chest receive an appropriateness score of 2 (rarely appropriate).

Category 1, Scenario 3: Bone scan $\left({ }^{99 m}\right.$ Tc-Methylene Diphosphonate [MDP] WB Scan, ${ }^{18}$ F-Sodium Fluoride [NaF] PET/CT) (Score 8-Appropriate). In the clinical setting of primary staging, current National Comprehensive Cancer Network (NCCN) guidelines recommend an imaging evaluation with a bone scan in any patient with a PSA level of $>20 \mathrm{ng} / \mathrm{mL}$, a Gleason score of 8 or greater, or a clinical stage of $\mathrm{T} 3$ or greater (high-risk and very highrisk groups) and in patients with any of 2 of the following: a PSA level of $>10 \mathrm{ng} / \mathrm{mL}$, a Gleason score of 7 or over, and a clinical stage of $\mathrm{T} 2 \mathrm{~b} / \mathrm{T} 2 \mathrm{c}$ or greater (intermediate-unfavorable group). A recent systematic review of 54 studies encompassing a total sample size of 20,421 patients with treatment-naive cancer found yield rates of $4 \%$ with a PSA level of $\leq 10 \mathrm{ng} / \mathrm{mL}, 7 \%$ with a PSA level of 10 to $\leq 20 \mathrm{ng} / \mathrm{mL}, 42 \%$ with a PSA level of $>20 \mathrm{ng} / \mathrm{mL}, 4.1 \%$ with a Gleason score of 6 or less, $10 \%$ with a Gleason score of 7 , and $28.79 \%$ with a Gleason score of 8 or greater (27). In subgroup analyses, a Gleason score of 7 with a PSA level of $<20 \mathrm{ng} / \mathrm{mL}$ had a $3 \%$ yield, whereas a Gleason score of 8 with a PSA level of $\leq$ $10 \mathrm{ng} / \mathrm{mL}$ had a yield of $20 \%$, suggesting that a bone scan would be useful with a PSA level of $>20 \mathrm{ng} / \mathrm{mL}$ or a Gleason score of 8 or over.

However, it is probable that the case for patients with BCR of prostate cancer is different. One study of 1,197 patients who had undergone RP found that those with a positive bone scan result always had a PSA level of at least $7 \mathrm{ng} / \mathrm{mL}$ (28), and another study of 100 patients after RP suggested an optimal trigger PSA level cutoff of $30-40 \mathrm{ng} / \mathrm{mL}$ (29). One study of 142 patients with PSA levels of up to $1 \mathrm{ng} / \mathrm{mL}$ after RP reported only a $2 \%$ bone scan yield (30). Therefore, these investigations suggest that the PSA trigger cutoff for a positive bone scan result in patients who have undergone RP may be in the range of $7-30 \mathrm{ng} / \mathrm{mL}$ and not lower.

The PSA velocity (i.e., the rate of change of serum PSA levels over time) may also be relevant. A study of 132 patients after RP suggested that the PSA velocity was more important, with $0.5 \mathrm{ng} /$ $\mathrm{mL} / \mathrm{mo}$ serving as an optimal cutoff (23). A study of 292 patients,

TABLE 2

CATEGORY 2: Clinical Scenarios for BCR After Prior Definitive Treatment with RP or RT-Negative Or Equivocal Results on Initial Standard Imaging

\begin{tabular}{|c|c|c|c|}
\hline Scenario no. & Description & Appropriateness & Score \\
\hline 1 & ${ }^{18}$ F-FDG PET/CT (skull base to midthigh) & Rarely appropriate & 2 \\
\hline 2 & ${ }^{11} \mathrm{C}$-choline PET/CT (skull base to midthigh) & Appropriate & 9 \\
\hline 3 & ${ }^{18} \mathrm{~F}$-fluciclovine PET/CT (skull base to midthigh) & Appropriate & 9 \\
\hline 4 & ${ }^{111}$ In-capromab pendetide & Rarely appropriate & 1 \\
\hline
\end{tabular}


most of whom had undergone RP, suggested a trigger PSA value of $5 \mathrm{ng} / \mathrm{mL}$ and a PSA doubling time of $10 \mathrm{mo}$ (31), whereas another study of 128 patients after RP suggested cutoffs of $10 \mathrm{ng} / \mathrm{mL}$ for the PSA value and 6 mo for the PSA doubling time (32). Another investigation of 438 patients after RP also incorporated the presence or absence of ADT. Whereas with patients before being treated with ADT, a threshold PSA doubling time of 9 mo was a fairly effective cutoff (yield of $1 \%-5 \%$ for $>9$ mo vs. $11 \%-44 \%$ for $<9 \mathrm{mo}$ ), for patients after ADT treatment, there was a yield of at least $10 \%$, even with long PSA doubling times and low PSA levels (below $10 \mathrm{ng} / \mathrm{mL}$ ) (33). A study of 239 patients used trigger PSA values and PSA slope and velocity to create a nomogram (34). The results concurred with the NCCN guidelines in recommending a bone scan with a PSA level of $20 \mathrm{ng} / \mathrm{mL}$, or with a PSA level of $10 \mathrm{ng} / \mathrm{mL}$ with a Gleason score of 7 or greater or stage T2 or greater; a PSA doubling time of 9 mo or less was added as another indication.

For ${ }^{18} \mathrm{~F}-\mathrm{NaF}$ PET, dedicated studies that focus specifically on recurrence are few, and these studies do not separate patients who have undergone RP from those who have undergone RT. Theoretically, the higher photon flux and coincidence detection with PET and concurrent CT should increase sensitivity and specificity, respectively, over a planar WB scan, and multiple studies, albeit mostly for initial staging (35) or mixed indications of initial staging and BCR (36-38). Interestingly, 1 study showed a decline in specificity from $82 \%$ to $54 \%$ (39), whereas another showed a small decrease from $88 \%$ to $82 \%$ vis-à-vis SPECT, but with an overall improvement in both sensitivity and specificity over a planar bone scan (40). Moreover, a large retrospective study of the National Oncologic PET Registry found a change in management over a bone scan in $12 \%-16 \%$ of cases (41). A recent study of 62 patients with mixed indications suggests a PSA cutoff of $6 \mathrm{ng} / \mathrm{mL}$ for previously treated patients, lower than that previously suggested for a bone scan (42).

A few studies have compared ${ }^{18} \mathrm{~F}-\mathrm{NaF}$ to other PET tracers. These generally do not separate RP from RT (43). Results of studies that compared ${ }^{18} \mathrm{~F}-\mathrm{NaF}$ to ${ }^{18} \mathrm{~F}$-fluorocholine are mixed. Some show increased sensitivity (for bone lesions) at the expense of specificity $(39,43)$. One study that focused on initial staging found a similar performance for bone lesions (44), whereas another, with a mix of initial and recurrent indications, showed some loss in specificity with ${ }^{18} \mathrm{~F}-\mathrm{NaF}$ (45). When ${ }^{18} \mathrm{~F}-\mathrm{FDG}$ and ${ }^{18} \mathrm{~F}-\mathrm{NaF}$ are compared, the latter is more sensitive for detecting bone metastases at BCR even at PSA levels as low as $2-4 \mathrm{ng} / \mathrm{mL}$, albeit at the expense of specificity (46-48). For PSMA tracers, mostly in a mixed primary and recurrent population, studies show a similar pattern, with ${ }^{18} \mathrm{~F}-\mathrm{NaF}$ detecting more bone lesions at the expense of decreased specificity (49-51); 1 study showed no significant difference (52). A consistent result is that, compared with other PET tracers, ${ }^{18} \mathrm{~F}-\mathrm{NaF}$ is more sensitive for bone lesions at the expense of specificity. It outperforms conventional ${ }^{99 \mathrm{~m}} \mathrm{Tc}$-based bone scans, which may be relevant in clinical management decisions (53). In summary, a bone scan is considered standard imaging and received an appropriateness score of 8 (appropriate).

Category 1, Scenario 4: MRI of the Pelvis With And Without Intravenous Contrast (Score 8-Appropriate). An MRI of the pelvis can be effective in identifying sites of recurrent prostate cancer and its use is rapidly increasing (54). Most studies demonstrate that an MRI of the pelvis is reliable for the detection of local recurrence either at the site of the prostate bed in patients who have undergone RP or within the prostate in patients after RT treatment (55-59). The combination of diffusion-weighted, T2weighted, and dynamic contrast enhancement MRI is particularly effective for detecting local recurrence $(58,60)$. For pelvic nodal metastatic detection, a pelvic MRI has similar limitations to that of $\mathrm{CT}$, namely, low sensitivity due to the dependence on size criteria. Many lymph nodes that test positive are too small to meet the 0.8to $1-\mathrm{cm}$ size threshold for positivity on MRI. Although there was initial enthusiasm for diffusion-weighted imaging for detecting normal-sized lymph nodes at initial staging, there is no evidence in the literature that this method is valid in patients with BCR (61), and the method has proven difficult outside of research settings. When lesions are present in the pelvic bones, MRI is highly sensitive, equaling PET scans in this regard, with the caveat that findings may not be specific for bone metastases (58). MRI can be predictive of response to salvage RT from the extent of the recurrent disease (62). Thus, a pelvic MRI provides useful information, in particular for local recurrence and bone metastases in the setting of BCR, which led to an appropriateness score of 8 (appropriate).

Category 1, Scenario 5: ${ }^{18}$ F-FDG PET/CT (Skull Base to Midthigh) (Score 2 - Rarely Appropriate). Category 2, Scenario 1: ${ }^{18}$ F-FDG PET/CT (Skull Base to Midthigh) (Score 2 - Rarely Appropriate). ${ }^{18} \mathrm{~F}-\mathrm{FDG}$ PET/CT has revolutionized the field of cancer imaging and has become one of the pillars of management of many cancers. This huge success is not reflected in prostate cancer, where many studies have documented disappointing detection capabilities or better alternative imaging tests. This is despite some results in the literature suggesting the potential utility of ${ }^{18} \mathrm{~F}$-FDG PET/CT in prostate cancer; this discrepancy is likely because of variability in the standards of reference used or changing paradigms in the management of BCR. For example, using standard definitions, Öztürk and Karapolat (63) evaluated ${ }^{18} \mathrm{~F}$ FDG PET/CT in 28 patients with BCR after RP or RT and found that imaging results were negative in $16(57.1 \%)$ patients and positive in $12(42.9 \%)$. However, no summary PSA statistics for the study group were included, and no mention of biopsy confirmation was made or other measures provided to assess the true positivity of the PET findings. Schöder et al. (64) reported sensitivities of $71 \%-80 \%$ and specificities of $73 \%-77 \%$ for ${ }^{18} \mathrm{~F}-\mathrm{FDG}$ PET in the recurrence setting, where the median PSA level was 2.4 $\mathrm{ng} / \mathrm{mL}$. These results probably overestimate the clinical utility of ${ }^{18}$ F-FDG PET/CT, given that many of the patients had positive findings on other standard imaging and the PSA thresholds are considerably above those that would trigger salvage RT in the contemporary setting (typically around $0.5 \mathrm{ng} / \mathrm{mL}$ ). In a subset of patients with early BCR after RP (PSA level $<1 \mathrm{ng} / \mathrm{mL}$ ), a more recent study reported ${ }^{18} \mathrm{~F}$-FDG PET positivity in only 1 of 5 patients; on directed biopsy, only inflammatory tissue was identified at the site of ${ }^{18} \mathrm{~F}-\mathrm{FDG}$ uptake in the thoracic spine (i.e., false positive) (30). Jadvar et al. (46) found ${ }^{18} \mathrm{~F}-\mathrm{FDG}$ PET/CT detection rates of only $8.1 \%$ in a prospective study of 37 patients with BCR and negative results of standard imaging. The same group published a comparative performance study of PET tracers in prostate cancer BCR and found that ${ }^{18} \mathrm{~F}-\mathrm{FDG}$ PET/CT exhibited the lowest detection rates compared with those of ${ }^{11} \mathrm{C}$-acetate, ${ }^{11} \mathrm{C}$ - or ${ }^{18} \mathrm{~F}$ choline, anti-1-amino-3-3 ${ }^{18} \mathrm{~F}$-fluorocyclobutane-1-carboxylic acid (FACBC or ${ }^{18} \mathrm{~F}$-fluciclovine), and radiolabeled ligand targeted to PSMA (65). However, ${ }^{18}$ F-FDG PET/CT may play a role later in the course of prostate cancer, particularly in the context of metastatic disease (66-69). In summary, ${ }^{18} \mathrm{~F}-\mathrm{FDG}$ PET/CT is rarely appropriate for the evaluation of $\mathrm{BCR}$ of prostate cancer after 
RP or RT, even in the context of negative or equivocal standard imaging results, leading to an appropriateness score of 2 (rarely appropriate).

Category 1, Scenario 6: ${ }^{11}$ C-Choline PET/CT (Skull Base to Midthigh) (Score 6 - May be Appropriate). Category 2, Scenario 2: ${ }^{11}$ C-Choline PET/CT (Skull Base to Midthigh) (Score 9 - Appropriate). ${ }^{11} \mathrm{C}$-choline $\mathrm{PET} / \mathrm{CT}$ has long been used in $\mathrm{BCR}$ and is currently incorporated into NCCN and European Association of Urology guidelines. ${ }^{11} \mathrm{C}$-choline was approved in the United States on September 12, 2012, for PET imaging in recurrent prostate cancer $(70)$. The fluorinated choline radiotracer $\left({ }^{18} \mathrm{~F}\right.$-fluorocholine) has also been investigated relatively extensively and is used clinically in many countries; however, the radiotracer is not FDA approved. Although the literature on ${ }^{11} \mathrm{C}$-choline PET/CT is relatively robust, most reports are retrospective and rarely compare ${ }^{11} \mathrm{C}$-choline PET/CT to standard imaging (abdominopelvic CT, bone scan, and pelvis MRI). This is particularly true for patients with prior definitive treatment with RT, for which only 2 retrospective studies have been reported $(71,72)$. A first metaanalysis provided a pooled sensitivity of $85.6 \%$ (95\% confidence interval [CI]: $82.9 \%-88.1 \%$ ) and a pooled specificity of $92.6 \%$ (95\% CI: $90.1 \%-94.6 \%$ ) for all sites of disease (73). A more recent metaanalysis (74), which considered only ${ }^{11} \mathrm{C}$-choline, reported a pooled sensitivity of $89 \%$ (95\% CI: $83 \%-93 \%$ ) and a pooled specificity of $89 \%$ (95\% CI: $73 \%-96 \%)$. For local relapse, the pooled sensitivity was $61 \%$ (95\% CI: $40 \%-80 \%)$ and the pooled specificity $97 \%$ (95\% CI: $87 \%-99 \%$ ); for nodal disease, the pooled detection rate was $36 \%$ (95\% CI: $22 \%-50 \%$ ), whereas for bone metastases, the pooled detection rate was $25 \%$ (95\% CI: $16 \%-34 \%$ ). As with all PET imaging methods, choline PET/CT sensitivity is strongly dependent on the PSA level and kinetics (velocity, doubling time, acceleration) (75). In patients with BCR after RP, choline PET/CT detection rates are only 5\%$24 \%$ when the PSA level is $<1 \mathrm{ng} / \mathrm{mL}$, but rises to $67 \%-100 \%$ when the PSA level is $>5 \mathrm{ng} / \mathrm{mL}$. Therefore, a PSA cutoff level of between 1 and $2 \mathrm{ng} / \mathrm{mL}$ has been suggested for choline PET/CT imaging. It may also be advantageous to consider PSA kinetics rather than PSA levels (76). In balancing its strengths (relatively abundant literature despite its stated limitations, FDA approval, incorporation into patient management guidelines) and weaknesses (need for on-site cyclotron and hence less accessibility, relatively high cost), the panel assessed that ${ }^{11} \mathrm{C}$-choline PET/CT may be appropriate (appropriateness score of 6) for the first imaging approach in patients with BCR in comparison to the widely available and less costly standard imaging. However, in patients with negative or equivocal conventional imaging results, the appropriateness score was raised to 9 (appropriate).

Category 1, Scenario 7: ${ }^{18}$ F-Fluciclovine PET/CT (Skull Base to Midthigh) (Score 6 - May be Appropriate). Category 2, Scenario 3: ${ }^{18}$ F-Fluciclovine PET/CT (Skull Base to Midthigh) (Score 9 - Appropriate). ${ }^{18}$ F-fluciclovine (Axumin) was FDA approved on May 26, 2016, for PET imaging in men with suspected prostate cancer recurrence based on elevated PSA levels after prior treatment (77). It was prospectively shown in 89 patients that ${ }^{18} \mathrm{~F}$ fluciclovine, in comparison to ${ }^{11} \mathrm{C}$-choline, is generally superior for detection of recurrence, especially for PSA values of $<2 \mathrm{ng} / \mathrm{mL}$ ( ${ }^{18} \mathrm{~F}$-fluciclovine vs. ${ }^{11} \mathrm{C}$-choline: $21 \%$ vs. $14 \%$ for PSA level of $<1 \mathrm{ng} / \mathrm{mL}, 29 \%$ vs. $29 \%$ for PSA level of 1 to $<2 \mathrm{ng} / \mathrm{mL}, 45 \%$ vs. $36 \%$ for PSA level of 2 to $<3 \mathrm{ng} / \mathrm{mL}$, and $59 \%$ vs. $50 \%$ for PSA level of $\geq 3 \mathrm{ng} / \mathrm{mL}$ ) (78). The overall sensitivity, specificity, and positive predictive values were $37 \%, 67 \%$, and $97 \%$, respectively, for ${ }^{18} \mathrm{~F}$-fluciclovine and $32 \%, 40 \%$, and $90 \%$, respectively, for ${ }^{11} \mathrm{C}$-choline. In a large multisite study with 596 patients, an overall detection rate of $68 \%$ was reported. ${ }^{18} \mathrm{~F}$-fluciclovine uptake suspicious for disease recurrence was found in the prostate bed and pelvic lymph node regions in $39 \%$ and $33 \%$ of scans, respectively. Metastatic involvement outside the pelvis was detected in $27 \%$ of scans. The corresponding positive predictive value was $62 \%$ for all detected lesions, with $92 \%$ for extraprostatic involvement and $72 \%$ for prostate/bed involvement (79). Another recent study that focused on patients with a PSA level of $\leq 1$ $\mathrm{ng} / \mathrm{mL}$ reported an overall positive lesion detection rate of $46.4 \%$, with local and nodal recurrences detected more often than distant metastases, and with a Gleason score of greater than 7 associated with positive scan results (80). The use of ${ }^{18} \mathrm{~F}$-fluciclovine PET/ CT has an impact on the clinical management of patients with BCR of prostate cancer. The prospective multicenter LOCATE trial reported a change in management in $59 \%$ of patients. Within this cohort, there were changes from salvage or noncurative systematic therapy to watchful waiting in $25 \%$ of patients, from noncurative systematic therapy to salvage therapy in $24 \%$, and from salvage therapy to noncurative systemic therapy in $9 \%$ (81). Another investigation reported change in salvage RT management of $41 \%$ of patients who had undergone a prostatectomy (82). Although not as sensitive as PSMA-targeted PET agents, ${ }^{18} \mathrm{~F}$-fluciclovine is nevertheless approved in the United States in the setting of recurrent disease. Similar to its consideration of ${ }^{11} \mathrm{C}$-choline, the panel assessed that ${ }^{18} \mathrm{~F}$-fluciclovine PET/CT may be appropriate (appropriateness score of 6) as the first imaging approach in patients with BCR in comparison to the widely available and lower cost standard imaging. However, in the setting of negative or equivocal conventional imaging results, the panel recommended a score of 9 (appropriate) for ${ }^{18} \mathrm{~F}$-fluciclovine.

Category 1, Scenario 8: ${ }^{111}$ In-Capromab Pendetide (Score 1 Rarely Appropriate). Category 2, Scenario 4: ${ }^{111}$ In-Capromab Pendetide (Score 1 - Rarely Appropriate). ${ }^{111}$ In-capromab pendetide is a radioimmunoconjugate consisting of the murine IgG1 $\kappa$-monoclonal antibody capromab (7E11-C5.3) conjugated to the linker-chelator glycyl-tyrosyl-(N,-diethylenetriaminepentaacetic acid)lysine hydrochloride (GYK-DTPA-HCl) and labeled with radioisotope ${ }^{111} \mathrm{In}$, with ligand-binding and $\gamma$-emitting activities. It binds to a cytoplasmic epitope of human PSMA, a cell transmembrane glycoprotein abundantly expressed by prostate epithelium, and is typically overexpressed by prostate cancer cells (83). Radioimmunoscintigraphy imaging with ${ }^{111}$ In-capromab pendetide was approved by the FDA on October 28, 1996, as a diagnostic imaging agent in newly diagnosed patients with biopsy-proven prostate cancer (84).

The utility of imaging with ${ }^{111}$ In-capromab pendetide for prostate cancer has been the subject of continual debate since its approval. Its disappointing low levels of both sensitivity and specificity significantly limited its use and acceptance. This seems to be an inherent property of the labeled antibody, which has not been shown to yield progressively better accuracy with the experience of the image interpreter, likely because of the agent's dependence on cytoplasmic binding, which achieves better results with nonviable than with viable tumor tissue. Another major limitation of this agent is that the antibody remains in the blood, leading to high background signals and consequently reduced target-to-background ratios and detection rates.

In a study of 30 men with biochemical relapse after prostatectomy who received salvage RT, ${ }^{111} \mathrm{In}$-capromab pendetide scan 
results were compared with postsalvage RT PSA response (85). In these patients, presalvage RT ${ }^{111}$ In-capromab pendetide scan findings outside the prostate fossa were not predictive of biochemical control after RT. Pucar et al. (86) concluded that ${ }^{111}$ In-capromab pendetide had "no added benefit over other imaging modalities [available at that time] in evaluating postradical prostatectomy recurrence, due to its low sensitivity for detecting local recurrences and bone metastases." Another study evaluated ${ }^{111}$ In-capromab pendetide against ${ }^{18} \mathrm{~F}$-fluciclovine $(87,88)$. It found that PET/CT with ${ }^{18} \mathrm{~F}$-fluciclovine demonstrated superior sensitivity, specificity, and accuracy to that of ${ }^{111} \mathrm{In}$-capromab for the detection of disease, both in the prostatic bed and in extraprostatic sites.

Notably, despite FDA approval and widespread use of ${ }^{111} \mathrm{In}$ capromab pendetide in the United States for more than $22 \mathrm{y}$, many health insurance providers will still not provide standard insurance coverage for imaging with ${ }^{111}$ In-capromab pendetide for prostate cancer, which continues to be categorized as "investigational," with the notation that the current medical literature "is insufficient to support conclusions concerning efficacy, optimal use and impact on the diagnosis, treatment or clinical management of prostate cancer using radioimmunoscintigraphy imaging with ${ }^{111}$ In capromab pendetide" $(89,90)$. Thus, ${ }^{111}$ In-capromab pendetide (marketed exclusively as ProstaScint) is no longer recommended in the setting of BCR. As of July 9, 2018, the FDA also reports on their website that Aytu BioScience, the manufacturer of ProstaScint, reported voluntary discontinuation of the product (91). As a result, the panel assigned an appropriateness score of 1 (rarely appropriate) to ${ }^{111}$ In-capromab pendetide.

\section{QUALIFYING STATEMENTS}

\section{Special Commentary}

In addition to the currently approved radiotracers for imaging of prostate cancer $\left({ }^{18} \mathrm{~F}\right.$-fluciclovine and ${ }^{11} \mathrm{C}$-choline), a new class of radiotracers has been developed that targets the PSMA $(92,93)$. The most commonly used compound is ${ }^{68}$ Ga-PSMA-11, which is limited in production and distribution, as it is labeled with ${ }^{68} \mathrm{Ga}$ (half-life $=68 \mathrm{~min}$ ) and is not yet approved in the United States $(94,95) .{ }^{68} \mathrm{Ga}$-PSMA-11 has been shown to have a higher detection sensitivity compared with that of ${ }^{18} \mathrm{~F}$-fluorocholine $(96,97)$ and has also recently been compared with ${ }^{18} \mathrm{~F}$-fluciclovine and shown to be superior in lesion detection $(98,99)$. Recently, a 635-patient single-arm clinical trial of ${ }^{68} \mathrm{Ga}-\mathrm{PSMA}-11$ demonstrated substantial interreader reproducibility and high detection sensitivity and accuracy compared with a composite endpoint in patients with BCR (100). ${ }^{68} \mathrm{Ga}$-PSMA-11 PET localized recurrent prostate cancer in $75 \%$ of patients; detection rates significantly increased with PSA level: $38 \%$ for $<0.5 \mathrm{ng} / \mathrm{mL}, 57 \%$ for 0.5 to $<$ $1.0 \mathrm{ng} / \mathrm{mL}, 84 \%$ for 1.0 to $<2.0 \mathrm{ng} / \mathrm{mL}, 86 \%$ for 2.0 to $<5.0$ $\mathrm{ng} / \mathrm{mL}$, and $97 \%$ for $\geq 5.0 \mathrm{ng} / \mathrm{mL}$. PSMA PET resulted in changes in RT plans in $53 \%$ of patients undergoing definitive RT $(101,102)$. In the salvage setting, Calais et al. $(103,104)$ showed that of 270 patients with a PSA level of $<1 \mathrm{ng} / \mathrm{mL}$, use of ${ }^{68} \mathrm{Ga}$-PSMA$11 \mathrm{PET} / \mathrm{CT}$ had a major impact on RT planning in 19\%, justifying a randomized imaging trial of salvage RT.

Although much of the data with PSMA-targeted PET radiotracers have focused on ${ }^{68} \mathrm{Ga}$-labeled agents, the use of ${ }^{18} \mathrm{~F}$ as a radionuclide has several advantages, including nearly unlimited cyclotron-based production, feasible central distribution due to a 110 -min physical half-life (vs. $68 \mathrm{~min}$ for ${ }^{68} \mathrm{Ga}$ ), higher positron yield, and lower positron energy (leading to shorter positron annihilation distances and higher spatial resolution) $(105,106)$. These intrinsic advantages may lead to the widespread adoption of ${ }^{18} \mathrm{~F}$-labeled ligands as the worldwide demand for PSMA-targeted radiotracers continues to increase. ${ }^{18} \mathrm{~F}$-labeled PSMA-targeted radiotracers have shown high sensitivity for the detection of putative sites of prostate cancer in men with $\mathrm{BCR}$ after attempted curative therapy. More recently, Giesel et al. (107) used a different ${ }^{18} \mathrm{~F}$-labeled radiotracer known as ${ }^{18} \mathrm{~F}$-PSMA-1007 in a retrospective analysis of 251 patients with BCR of prostate cancer. This tracer exhibits more hepatic and less renal excretion, potentially simplifying evaluation of the pelvis. In total, 204 of $251(81.3 \%)$ patients had findings on ${ }^{18} \mathrm{~F}$-PSMA-1007 PET deemed to be evidence of a site or sites of recurrent disease. The patient detection efficiency at the PSA range of $0.2-0.5 \mathrm{ng} / \mathrm{mL}$ was 40 of $65(61.5 \%)$. In another prospective investigation with ${ }^{18} \mathrm{~F}$-DCPyL PET/CT in 31 patients with BCR after RP, the positive detection rate was $59.1 \%$ in patients with a PSA level of $<1.0 \mathrm{ng} / \mathrm{mL}$ and $88.9 \%$ in patients with a PSA level of $>1.0 \mathrm{ng} / \mathrm{mL}$ (108). Rousseau et al. (109) reported a similar high detection efficacy with ${ }^{18}$ F-DCFPyL in 130 patients with BCR after curative intent primary therapy, with positive findings in $60 \%$ (PSA level $\geq 0.4$ to $<0.5 \mathrm{ng} / \mathrm{mL}$ ), $78 \%$ ( $\geq 0.5$ to $<1.0 \mathrm{ng} / \mathrm{mL}$ ), $72 \%$ ( $\geq 1.0$ to $<2.0 \mathrm{ng} / \mathrm{mL}$ ), and $92 \%$ ( $\geq 2.0 \mathrm{ng} / \mathrm{mL}$ ) of cases. Currently, it is unclear whether there is a benefit of one PSMA targeted agent over another, but because of the physical advantages of ${ }^{18} \mathrm{~F}$-labeled compounds, they will likely play a dominant role after they have been approved and become available.

In summary, PSMA PET is anticipated to have a significant role in the imaging evaluation of patients with BCR given its higher sensitivity and accuracy, although currently we are awaiting approval of these agents in the United States. Aside from regulatory approval, ongoing and future prospective investigations will be needed to examine how PSMA-based theranostics provide added clinical value and have an impact on treatment strategy, patient outcome, and relative economic outlay (110).

\section{IMPLEMENTATION OF THE AUC GUIDANCE}

SNMMI has been developing the AUC for high-value nuclear medicine procedures since early 2015 . This initiative was primarily undertaken to assist referring physicians and ordering professionals fulfill the requirements of the 2014 Protecting Access to Medicare Act (PAMA). Section 218(b) of PAMA established a new program under the statute for fee-for-service Medicare to promote the use of AUC for Advanced Diagnostic Imaging Services (ADIS), including CT, MRI, and all nuclear medicine procedures such as PET. PAMA requires referring physicians to consult AUC developed by a Centers for Medicare and Medicaid Services (CMS)-approved qualified provider-led entity, or Q-PLE, to ensure cost-effective and appropriate use of ADIS. After going through a rigorous and extensive application that required SNMMI to document their guideline development process, including COI adjudication and composition of expert panels, the society was approved as a Q-PLE in June 2016.

The PAMA legislation requiring the development of AUC also stipulated the mechanism of their delivery through a "qualified clinical decision support mechanism" (Q-CDSM) before ordering any advanced imaging. Therefore, successful implementation and complete adoption of this program relies on integration of AUC developed by PLEs into these Q-CDSMs. The society has partnered with leading CDSM providers to facilitate the adoption and use of SNMMI AUC. 
TABLE 3

Relationships with Industry and Other Entities

\begin{tabular}{|c|c|}
\hline Workgroup member & Reported relationships \\
\hline Ballas, Leslie & - None \\
\hline Choyke, Peter & - None \\
\hline \multirow[t]{2}{*}{ Fanti, Stefano } & $\begin{array}{l}\text { - Bayer-Italy, Participation } \\
\text { at Congress }\end{array}$ \\
\hline & - Bayer-Europe \\
\hline Gulley, James & - None \\
\hline Herrmann, Ken & - None \\
\hline Hope, Thomas & $\begin{array}{l}\text { - GE Healthcare, Speakers } \\
\text { Bureau, PET/MRI }\end{array}$ \\
\hline Jadvar, Hossein & - None \\
\hline Klitzke, Alan & - None \\
\hline Olden, Jorge & - None \\
\hline Pomper, Martin & $\begin{array}{l}\text { Cyclotek, Royalties, } \\
\text { Radiotracer }\end{array}$ \\
\hline Rowe, Steven & $\begin{array}{l}\text { - Progenics Pharmaceuticals, } \\
\text { Inc, Research Support, } \\
\text { Prostate Cancer }\end{array}$ \\
\hline Subramaniam, Rathan & - None \\
\hline Taneja, Samir & - None \\
\hline Vargas, Hebert Alberto & - None \\
\hline
\end{tabular}

After getting delayed for a couple of years, the implementation of the AUC program finally began in January 2020. CMS has tried to provide ample time to referring physicians and health-care institutions to comply with the legislative requirements for this program. Additional guidance related to priority clinical areas, exceptions for the ordering professionals for whom consultation with AUC would pose significant hardship, as well as for the physicians falling under the outlier category are expected in the upcoming Medicare Physician Fee Schedules.

\section{ACKNOWLEDGMENTS}

The workgroup acknowledges staff support from the Pacific Northwest Evidence-Based Practice Center of Oregon Health and Science University (Roger Chou, MD, FACP, Director, and Miranda Pappas, MA, Project Manager, Research Associate).

\section{APPENDIX A: WORKGROUP MEMBERS AND EXTERNAL REVIEWERS}

\section{Workgroup}

The members of the workgroup are Hossein Jadvar, MD, PhD, MPH, MBA (Chair), University of Southern California Keck School of Medicine, Los Angeles, CA (SNMMI); Leslie K. Ballas, MD, University of Southern California Keck School of Medicine, Los Angeles, CA (ASTRO); Peter L. Choyke, MD, National Institutes of Health, Bethesda, MD (ASCO); Stefano Fanti, MD, University of Bologna, Bologna, Italy (EANM); James L. Gulley, MD, PhD, National Institutes of Health, Bethesda, MD (ACP); Ken Herrmann, MD, Department of Nuclear Medicine, Universitätsklinikum Essen, Essen, Germany, and Department of Molecular and Medical Pharmacology, David Geffen School of
Medicine at UCLA, Los Angeles, CA (EANM); Thomas A. Hope, MD, University of California San Francisco, San Francisco, CA (SNMMI); Alan K. Klitzke, MD, Roswell Comprehensive Cancer Center, Buffalo, NY (ACNM); Jorge Oldan, MD, University of North Carolina, Chapel Hill Hospitals, Chapel Hill, NC (ASCO, SNMMI); Martin G. Pomper, MD, PhD, Johns Hopkins University Medical School, Baltimore, MD (WMIS); Steven P. Rowe, MD, $\mathrm{PhD}$, Johns Hopkins University Medical School, Baltimore, MD (SNMMI); Rathan M. Subramaniam, MD, PhD, MPH, University of Texas Southwestern Medical Center, Dallas, TX (ACNM, ACR); Samir S. Taneja, MD, NYU Langone Medical Center, New York, NY (AUA); Herbert Alberto Vargas, MD, Memorial Sloan Kettering Cancer Center, New York, NY (ASCO).

\section{External Reviewers}

The external (peer) reviewers were Soroush Rais-Bahrami, MD, University of Alabama, Birmingham, AL; Andrei Purysko, MD, Cleveland Clinic, Cleveland, OH; Jefferey Weinreb, MD, YaleNew Haven Hospital, New Haven, CT; Laura Evangelista, MD, $\mathrm{PhD}$, Istituto Oncologico Veneto IOV - IRCCS Padova, Italy; Bridget F. Koontz, MD, Duke University, Durham, NC; Mack Roach III, MD, University of California, San Francisco, CA.

\section{SNMMI}

The supporting staff from SNMMI are Sukhjeet Ahuja, MD, MPH, Sr. Director, Health Policy \& Quality Department; Teresa Ellmer, MIS, CNMT, Senior Program Manager, Health Policy \& Quality Department; Julie Kauffman, Program Manager, Health Policy \& Quality Department.

\section{APPENDIX B: DISCLOSURES AND CONFLICTS OF INTEREST (COIS)}

SNMMI rigorously attempted to avoid any actual, perceived, or potential COIs that might have arisen as a result of an outside relationship or personal interest on the part of the workgroup members or external reviewers. Workgroup members were required to provide disclosure statements of all relationships that might be perceived as real or potential COIs. These statements were reviewed and discussed by the workgroup chair and SNMMI staff and were updated and reviewed by an objective third party at the beginning of every workgroup meeting or teleconference. The disclosures of the workgroup members can be found in Table 3. A COI was defined as a relationship with industry-including consulting, speaking, research, and nonresearch activities-that exceeds $\$ 5,000$ in funding over the previous or upcoming 12month period. In addition, if an external reviewer was either the principal investigator of a study or another key member of the study personnel, that person's participation in the review was considered likely to present a COI. All reviewers were asked about any potential COI. A COI was also considered likely if an external reviewer or workgroup member was either the principal investigator or a key member of a study directly related to the content of this AUC. All external reviewers were asked about any potential COI.

\section{APPENDIX C: PUBLIC COMMENTARY}

The workgroup solicited information from all communities through the SNMMI website and through direct solicitation of SNMMI members. The comments and input helped to shape the development of these AUC on imaging evaluation of BCR of prostate cancer after definitive primary treatment. 


\section{REFERENCES}

1. Crawford ED, Koo PJ, Shore N, et al. A clinician's guide to next generation imaging in patients with advanced prostate cancer (RADAR III). J Urol. 2019;201: 682-692.

2. Perez-Lopez R, Tiunariu N, Padhani AR, et al. Imaging diagnosis and follow-up of advanced prostate cancer: clinical perspectives and state of the art. Radiology. 2019;292:273-286.

3. Protecting Access to Medicare Act of 2014, Pub L No. 113-93, 128 Stat 1040 (2014).

4. Bray F, Ferlay J, Soerjomataram I, Siegel RL, Torre LA, Jemal A. Global cancer statistics 2018: GLOBOCAN estimates of incidence and mortality worldwide for 36 cancers in 185 countries. CA Cancer J Clin. 2018;68:394-424.

5. Siegel RL, Miller KD, Jemal A. Cancer statistics, 2018. CA Cancer J Clin. 2018;68:7-30.

6. Mullins JK, Feng Z, Trock BJ, Epstein JI, Walsh PC, Loeb S. The impact of anatomical radical retropubic prostatectomy on cancer control: the 30-year anniversary. J Urol. 2012;188:2219-2224.

7. Cookson MS, Aus G, Burnett AL, et al. Variation in the definition of biochemical recurrence in patients treated for localized prostate cancer update panel report and recommendations for standard in the reporting of surgical outcomes. J Urol. 2007;177:540-545.

8. Roach M, 3rd, Hanks G, Thames H Jr, et al. Defining biochemical failure following radiation therapy with or without hormonal therapy in men with clinically localized prostate cancer: recommendations of the RTOG-ASTRO Phoenix Consensus Conference. Int J Radiat Oncol Biol Phys. 2006;65:965974.

9. Freedland SJ, Humphreys EB, Mangold LA, et al. Risk of prostate cancerspecific mortality following biochemical recurrence after radical prostatectomy. JAMA. 2005;294:433-439.

10. Antonarakis ES, Feng Z, Trock BJ, et al. The natural history of metastatic progression in men with prostate-specific antigen recurrence after radical prostatectomy: long-term follow-up. BJU Int. 2012;109:32-39.

11. Stephenson AJ, Scardino PT, Kattan MW, et al. Predicting the outcome of salvage radiation therapy for recurrent prostate cancer after radical prostatectomy. J Clin Oncol. 2007;25:2035-2041.

12. Dalela D, Löppenberg B, Sood A, Sammon J, Abdollah F. Contemporary role of the Decipher ${ }^{\circledR}$ test in prostate cancer management: current practice and future perspectives. Rev Urol. 2016;18:1-9.

13. Xu MJ, Kornberg Z, Gadzinski AJ, et al. Genomic risk predicts molecular imaging-detected metastatic nodal disease in prostate cancer. Eur Urol Oncol. January 14, 2019 [Epub ahead of print].

14. Pollack A, Karrison TG, Balogh AG, et al. Short term androgen deprivation therapy without or with pelvic lymph node treatment added to prostate bed only salvage radiotherapy: The NRG Oncology/RTOG 0534 SPPORT trial. Int J Radiat Oncol Biol Phys. 2018;102:1605.

15. Jadvar H. Oligometastatic prostate cancer: molecular imaging and clinical management implications in the era of precision oncology. J Nucl Med. 2018;59:13381339.

16. Muldermans JL, Romak LB, Kwon ED, Park SS, Olivier KR. Stereotactic body radiation therapy for oligometastatic prostate cancer. Int J Radiat Oncol Biol Phys. 2016;95:696-702.

17. Ost P, Jereczek-Fossa BA, As NV, et al. Progression-free survival following stereotactic body radiotherapy for oligometastatic prostate cancer treatmentnaive recurrence: a multi-institutional analysis. Eur Urol. 2016;69:9-12.

18. Brassetti A, Proietti F, Pansadoro V. Oligometastic prostate cancer and salvage lymph node dissection: systematic review. Minerva Chir. 2019;74:97-106.

19. Fitch K, Bernstein SJ, Aguilar MD, Burnand B. The RAND/UCLA Appropriateness Method User's Manual. Santa Monica, CA: RAND; 2001.

20. Institute of Medicine of the National Academy. Clinical Practice Guidelines We Can Trust. Washington, DC: National Academies Press; 2011.

21. AQA Principles for Appropriateness Criteria. London, U.K.: Assessment and Qualifications Alliance; 2009.

22. Oyen RH, Van Poppel HP, Ameye FE, Van de Voorde WA, Baert AL, Baert LV. Lymph node staging of localized prostatic carcinoma with CT and CT-guided fine-needle aspiration biopsy: prospective study of 285 patients. Radiology. 1994; 190:315-322.

23. Kane CJ, Amling CL, Johnstone PA, et al. Limited value of bone scintigraphy and computed tomography in assessing biochemical failure after radical prostatectomy. Urology. 2003;61:607-611.

24. Johnstone PA, Tarman GJ, Riffenburgh R, Rohde DC, Puckett ML, Kane CJ. Yield of imaging and scintigraphy assessing biochemical failure in prostate cancer patients. Urol Oncol. 1997;3:108-112.
25. Spencer JA, Golding SJ. Patterns of lymphatic metastases at recurrence of prostate cancer: CT findings. Clin Radiol. 1994;49:404-407.

26. Lamothe F, Kovi J, Heshmat MY, Green EJ. Dissemination of prostate carcinoma: an autopsy study. J Natl Med Assoc. 1986;78:1083-1086.

27. Suh $\mathrm{CH}$, Shinagare AB, Westenfield AM, Ramaiya NH, Van den Abbeele AD, Kim KW. Yield of bone scintigraphy for the detection of metastatic disease in treatment-naive prostate cancer: a systematic review and meta-analysis. Clin Radiol. 2018;73:158-167.

28. Gomez P, Manoharan M, Kim SS, Soloway MS. Radionuclide bone scintigraphy in patients with biochemical recurrence after radical prostatectomy: when is it indicated? BJU Int. 2004;94:299-302.

29. Cher ML, Bianco FJ Jr, Lam JS, et al. Limited role of radionuclide bone scintigraphy in patients with prostate specific antigen elevations after radical prostatectomy. J Urol. 1998;160:1387-1391.

30. Vargas HA, Martin-Malburet AG, Takeda T, et al. Localizing sites of disease in patients with rising serum prostate-specific antigen up to $1 \mathrm{ng} / \mathrm{ml}$ following prostatectomy: how much information can conventional imaging provide? Urol Oncol. 2016;34:482.e5-482.e10.

31. Choueiri TK, Dreicer R, Paciorek A, Carroll PR, Konety B. A model that predicts the probability of positive imaging in prostate cancer cases with biochemical failure after initial definitive local therapy. J Urol. 2008;179:906-910.

32. Okotie OT, Aronson WJ, Wieder JA, et al. Predictors of metastatic disease in men with biochemical failure following radical prostatectomy. J Urol. 2004;171: 2260-2264.

33. Moreira DM, Cooperberg MR, Howard LE, et al. Predicting bone scan positivity after biochemical recurrence following radical prostatectomy in both hormone-naive men and patients receiving androgen-deprivation therapy: results from the SEARCH database. Prostate Cancer Prostatic Dis. 2014;17:91-96.

34. Dotan ZA, Bianco FJ Jr, Rabbani F, et al. Pattern of prostate-specific antigen (PSA) failure dictates the probability of a positive bone scan in patients with an increasing PSA after radical prostatectomy. J Clin Oncol. 2005;23:1962-1968.

35. Wondergem M, van der Zant FM, Knol RJJ, et al. ${ }^{99 \mathrm{~m}} \mathrm{Tc}-\mathrm{HDP}$ bone scintigraphy and ${ }^{18} \mathrm{~F}$-sodium fluoride PET/CT in primary staging of patients with prostate cancer. World J Urol. 2018;36:27-34.

36. Apolo AB, Lindenberg L, Shih JH, et al. Prospective study evaluating Na18F $\mathrm{PET} / \mathrm{CT}$ in predicting clinical outcomes and survival in advanced prostate cancer. J Nucl Med. 2016;57:886-892.

37. Schirrmeister H, Guhlmann A, Elsner K, et al. Sensitivity in detecting osseous lesions depends on anatomic localization: planar bone scintigraphy versus ${ }^{18} \mathrm{~F}$ PET. J Nucl Med. 1999;40:1623-1629.

38. Even-Sapir E, Metser U, Mishani E, Lievshitz G, Lerman H, Leibovitch I. The detection of bone metastases in patients with high-risk prostate cancer: ${ }^{99 \mathrm{~m} T c-}$ MDP planar bone scintigraphy, single- and multi-field-of-view SPECT, ${ }^{18} \mathrm{~F}$ fluoride PET, and ${ }^{18}$ F-fluoride PET/CT. J Nucl Med. 2006;47:287-297.

39. Poulsen MH, Petersen H, Hoilund-Carlsen PF, et al. Spine metastases in prostate cancer: comparison of technetium-99m-MDP whole-body bone scintigraphy, $\left[{ }^{18} \mathrm{~F}\right]$ choline positron emission tomography(PET)/computed tomography (CT) and $\left[{ }^{18} \mathrm{~F}\right] \mathrm{NaF}$ PET/CT. BJU Int. 2014;114:818-823.

40. Jambor I, Kuisma A, Ramadan S, et al. Prospective evaluation of planar bone scintigraphy, SPECT, SPECT/CT, ${ }^{18} \mathrm{~F}-\mathrm{NaF}$ PET/CT and whole body $1.5 \mathrm{~T}$ MRI, including DWI, for the detection of bone metastases in high risk breast and prostate cancer patients: SKELETA clinical trial. Acta Oncol. 2016;55:59-67.

41. Hillner BE, Siegel BA, Hanna L, et al. Impact of ${ }^{18} \mathrm{~F}$-fluoride PET on intended management of patients with cancers other than prostate cancer: results from the National Oncologic PET Registry. J Nucl Med. 2014;55:1054-1061.

42. Sarikaya I, Sarikaya A, Elgazzar AH, et al. Prostate-specific antigen cutoff value for ordering sodium fluoride positron emission tomography/computed tomography bone scan in patients with prostate cancer. World J Nucl Med. 2018;17:281-285.

43. Beheshti M, Vali R, Waldenberger P, et al. Detection of bone metastases in patients with prostate cancer by ${ }^{18} \mathrm{~F}$ fluorocholine and ${ }^{18} \mathrm{~F}$ fluoride PET-CT: a comparative study. Eur J Nucl Med Mol Imaging. 2008;35:1766-1774.

44. Kjölhede H, Ahlgren G, Almquist H, et al. Combined ${ }^{18} \mathrm{~F}$-fluorocholine and ${ }^{18} \mathrm{~F}$-fluoride positron emission tomography/computed tomography imaging for staging of high-risk prostate cancer. BJU Int. 2012;110:1501-1506.

45. Langsteger W, Balogova $\mathrm{S}$, Huchet V, et al. Fluorocholine $\left({ }^{18} \mathrm{~F}\right)$ and sodium fluoride $\left({ }^{18} \mathrm{~F}\right) \mathrm{PET} / \mathrm{CT}$ in the detection of prostate cancer: prospective comparison of diagnostic performance determined by masked reading. $Q \mathrm{~J} \mathrm{Nucl} \mathrm{Med}$ Mol Imaging. 2011;55:448-457.

46. Jadvar H, Desai B, Ji L, et al. Prospective evaluation of ${ }^{18} \mathrm{~F}-\mathrm{NaF}$ and ${ }^{18} \mathrm{~F}-\mathrm{FDG}$ $\mathrm{PET} / \mathrm{CT}$ in detection of occult metastatic disease in biochemical recurrence of prostate cancer. Clin Nucl Med. 2012;37:637-643.

47. Iagaru A, Mittra E, Dick DW, Gambhir SS. Prospective evaluation of ${ }^{99 \mathrm{~m}} \mathrm{Tc}$ MDP scintigraphy, ${ }^{18} \mathrm{~F} \mathrm{NaF} \mathrm{PET/CT,} \mathrm{and}{ }^{18} \mathrm{~F}$ FDG PET/CT for detection of skeletal metastases. Mol Imaging Biol. 2012;14:252-259. 
48. Damle NA, Bal C, Bandopadhyaya GP, et al. The role of ${ }^{18}$ F-fluoride PET-CT in the detection of bone metastases in patients with breast, lung and prostate carcinoma: a comparison with FDG PET/CT and ${ }^{99 \mathrm{~m} T c-M D P}$ bone scan. Jpn J Radiol. 2013;31:262-269.

49. Uprimny C, Svirydenka A, Fritz J, et al. Comparison of $\left[{ }^{68} \mathrm{Ga}\right] \mathrm{Ga}-\mathrm{PSMA}{ }^{-11}$ $\mathrm{PET} / \mathrm{CT}$ with $\left[{ }^{18} \mathrm{~F}\right] \mathrm{NaF}$ PET/CT in the evaluation of bone metastases in metastatic prostate cancer patients prior to radionuclide therapy. Eur J Nucl Med Mol Imaging. 2018;45:1873-1883.

50. Zacho HD, Nielsen JB, Afshar-Oromieh A, et al. Prospective comparison of ${ }^{68} \mathrm{Ga}$-PSMA PET/CT, ${ }^{18} \mathrm{~F}$-sodium fluoride PET/CT and diffusion weightedMRI at for the detection of bone metastases in biochemically recurrent prostate cancer. Eur J Nucl Med Mol Imaging. 2018;45:1884-1897.

51. Harmon SA, Bergvall E, Mena E, et al. A prospective comparison of ${ }^{18} \mathrm{~F}$ sodium fluoride PET/CT and PSMA-targeted ${ }^{18} \mathrm{~F}$-DCFBC PET/CT in metastatic prostate cancer. J Nucl Med. 2018;59:1665-1671.

52. Dyrberg E, Hendel HW, Huynh THV, et al. ${ }^{68} \mathrm{Ga}$-PSMA-PET/CT in comparison with ${ }^{18} \mathrm{~F}$-fluoride-PET/CT and whole-body MRI for the detection of bone metastases in patients with prostate cancer: a prospective diagnostic accuracy study. Eur Radiol. 2019;29:1221-1230.

53. Jadvar $\mathrm{H}$, Colletti PM. ${ }^{18} \mathrm{~F}-\mathrm{NaF} / 223 \mathrm{RaCl}_{2}$ theranostics in metastatic prostate cancer: treatment response assessment and prediction of outcome. Br J Radiol. 2018;91:20170948.

54. Oberlin DT, Casalino DD, Miller FH, Meeks JJ. Dramatic increase in the utilization of multiparametric magnetic resonance imaging for detection and management of prostate cancer. Abdom Radiol (NY). 2017;42:1255-1258.

55. Barchetti F, Stagnitti A, Megna V, et al. Unenhanced whole-body MRI versus PET-CT for the detection of prostate cancer metastases after primary treatment. Eur Rev Med Pharmacol Sci. 2016;20:3770-3776.

56. Couñago F, Sancho G, Catalá V, et al. Magnetic resonance imaging for prostate cancer before radical and salvage radiotherapy: what radiation oncologists need to know. World J Clin Oncol. 2017;8:305-319.

57. Hayman J, Hole KH, Seierstad T, et al. Local failure is a dominant mode of recurrence in locally advanced and clinical node positive prostate cancer patients treated with combined pelvic IMRT and androgen deprivation therapy. Urol Oncol. 2019;37:289.e19-289.e26.

58. Kitajima K, Murphy RC, Nathan MA, et al. Detection of recurrent prostate cancer after radical prostatectomy: comparison of ${ }^{11} \mathrm{C}$-choline PET/CT with pelvic multiparametric MR imaging with endorectal coil. J Nucl Med. 2014;55: 223-232.

59. Sobol I, Zaid HB, Haloi R, et al. Contemporary mapping of post-prostatectomy prostate cancer relapse with ${ }^{11} \mathrm{C}$-choline positron emission tomography and multiparametric magnetic resonance imaging. J Urol. 2017;197:129-134.

60. Giannarini G, Nguyen DP, Thalmann GN, Thoeny HC. Diffusion-weighted magnetic resonance imaging detects local recurrence after radical prostatectomy: initial experience. Eur Urol. 2012;61:616-620.

61. Thoeny HC, Froehlich JM, Triantafyllou M, et al. Metastases in normal-sized pelvic lymph nodes: detection with diffusion-weighted MR imaging. Radiology. 2014;273:125-135.

62. Sharma V, Nehra A, Colicchia M, et al. Multiparametric magnetic resonance imaging is an independent predictor of salvage radiotherapy outcomes after radical prostatectomy. Eur Urol. 2018;73:879-887.

63. Öztürk H, Karapolat I. ${ }^{18} \mathrm{~F}$-fluorodeoxyglucose PET/CT for detection of disease in patients with prostate-specific antigen relapse following radical treatment of a local-stage prostate cancer. Oncol Lett. 2016;11:316-322.

64. Schöder H, Herrmann K, Gönen M, et al. 2-[ $\left.{ }^{18} \mathrm{~F}\right]$ fluoro-2-deoxyglucose positron emission tomography for the detection of disease in patients with prostate-specific antigen relapse after radical prostatectomy. Clin Cancer Res. 2005;11:4761-4769.

65. Yu CY, Desai B, Ji L, Groshen SG, Jadvar H. Comparative performance of PET tracers in biochemical recurrence of prostate cancer: a critical analysis of literature. Am J Nucl Med Mol Imaging. 2014;4:580-601.

66. Fox JJ, Gavane SC, Blanc-Autran E, et al. Positron emission tomography/ computed tomography-based assessments of androgen receptor expression and glycolytic activity as a prognostic biomarker for metastatic castrationresistant prostate cancer. JAMA Oncol. 2018;4:217-224.

67. Jadvar H, Desai B, Ji L, et al. Baseline ${ }^{18} \mathrm{~F}$-FDG PET/CT parameters as imaging biomarkers of overall survival in castrate-resistant metastatic prostate cancer. J Nucl Med. 2013;54:1195-1201.

68. Vargas HA, Wassberg C, Fox JJ, et al. Bone metastases in castration-resistant prostate cancer: associations between morphologic CT patterns, glycolytic activity, and androgen receptor expression on PET and overall survival. Radiology. 2014;271:220-229.

69. Jadvar H, Velez EM, Desai B, Ji L, Colletti PM, Quinn DI. Prediction of time to hormonal treatment failure in metastatic castrate sensitive prostate cancer. $J \mathrm{Nucl}$ Med. 2019;60:1524-1530.
70. FDA approves ${ }^{11} \mathrm{C}$-choline for PET in prostate cancer. $J$ Nucl Med. 2012;53:11N.

71. Rybalov M, Breeuwsma AJ, Leliveld AM, Pruim J, Dierckx RA, de Jong IJ. Impact of total PSA, PSA doubling time and PSA velocity on detection rates of ${ }^{11} \mathrm{C}$-Choline positron emission tomography in recurrent prostate cancer. World J Urol. 2013;31:319-323.

72. Ceci F, Herrmann K, Castellucci P, et al. Impact of ${ }^{11} \mathrm{C}$-choline PET/CT on clinical decision making in recurrent prostate cancer: results from a retrospective two-center trial. Eur J Nucl Med Mol Imaging. 2014;41:2222-2231.

73. Evangelista L, Zattoni F, Guttilla A, et al. Choline PET or PET/CT and biochemical relapse of prostate cancer: a systematic review and meta-analysis. Clin Nucl Med. 2013;38:305-314.

74. Fanti S, Minozzi S, Castellucci P, et al. PET/CT with ${ }^{11} \mathrm{C}$-choline for evaluation of prostate cancer patients with biochemical recurrence: meta-analysis and critical review of available data. Eur J Nucl Med Mol Imaging. 2016;43:55-69.

75. Treglia G, Ceriani L, Sadeghi R, Giovacchini G, Giovanella L. Relationship between prostate-specific antigen kinetics and detection rate of radiolabelled choline PET/CT in restaging prostate cancer patients: a meta-analysis. Clin Chem Lab Med. 2014;52:725-733.

76. Castellucci P, Ceci F, Graziani T, et al. Early biochemical relapse after radical prostatectomy: which prostate cancer patients may benefit from a restaging ${ }^{11} \mathrm{C}$-choline PET/CT scan before salvage radiation therapy? J Nucl Med. 2014;55:1424-1429.

77. FDA approves new diagnostic imaging agent to detect recurrent prostate cancer [news release]. U.S. Food and Drug Administration; May 27, 2016. https://www.fda. gov/newsevents/newsroom/pressannouncements/ucm503920.htm. Accessed March 27, 2019.

78. Nanni C, Zanoni L, Pultrone C, et al. ${ }^{18} \mathrm{~F}-\mathrm{FACBC}$ (anti1-amino-3- ${ }^{18} \mathrm{~F}-$ fluorocyclobutane1-carboxylic acid) versus ${ }^{11} \mathrm{C}$-choline $\mathrm{PET} / \mathrm{CT}$ in prostate cancer relapse: results of a prospective trial. Eur J Nucl Med Mol Imaging. 2016;43:1601-1610.

79. Bach-Gansmo T, Nanni C, Nieh PT, et al. Multisite experience of the safety, detection rate and diagnostic performance of fluciclovine $\left({ }^{18} \mathrm{~F}\right)$ positron emission tomography/computerized tomography imaging in the staging of biochemically recurrent prostate cancer. J Urol. 2017;197:676-683.

80. England JR, Paluch J, Ballas LK, Jadvar H. ${ }^{18}$ F-fluciclovine PET/CT detection of recurrent prostate carcinoma in patients with serum PSA $\leq 1 \mathrm{ng} / \mathrm{mL}$ after definitive primary treatment. Clin Nucl Med. 2019;44:e128-e132.

81. Andriole GL, Kostakoglu L, Chau A, et al. The impact of positron emission tomography with ${ }^{18} \mathrm{~F}$-fluciclovine on the treatment of biochemical recurrence of prostate cancer: results from the LOCATE trial. J Urol. 2019;201:322-331.

82. Akin-Akintayo OO, Jani AB, Odewole $\mathrm{O}$, et al. Change in salvage radiotherapy management based on guidance with FACBC (fluciclovine) PET/CT in postprostatectomy recurrent prostate cancer. Clin Nucl Med. 2017;42:e22-e28.

83. Drug Dictionary NCI. Indium In 111 capromab pendetide. National Cancer Institute website. https://www.cancer.gov/publications/dictionaries/cancer-drug/ def/indium-in-111-capromab-pendetide. Accessed September 11, 2019.

84. Capromab pendetide. https://www.pharmacodia.com/yaodu/html/v1/biologics/ b4f1ec9f4b5c8207f8fc29522efe783d.html. Accessed September 11, 2019.

85. Thomas CT, Bradshaw PT, Pollock BH, et al. Indium-111-capromab pendetide radioimmunoscintigraphy and prognosis for durable biochemical response to salvage radiation therapy in men after failed prostatectomy. J Clin Oncol. 2003;21:1715-1721.

86. Pucar D, Sella T, Schöder H. The role of imaging in the detection of prostate cancer local recurrence after radiation therapy and surgery. Curr Opin Urol. 2008;18:87-97.

87. Schuster DM, Nieh PT, Jani AB, et al. Anti-3-[ $\left.{ }^{18} \mathrm{~F}\right] \mathrm{FACBC}$ positron emission tomography-computerized tomography and ${ }^{111}$ In-capromab pendetide single photon emission computerized tomography-computerized tomography for recurrent prostate carcinoma: results of a prospective clinical trial. J Urol. 2014;191:1446-1453.

88. Schuster DM, Savir-Baruch B, Nieh PT, et al. Detection of recurrent prostate carcinoma with anti-1-amino-3- ${ }^{18} \mathrm{~F}$-fluorocyclobutane-1-carboxylic acid PETCT and ${ }^{111}$ In-capromab pendetide SPECT/CT. Radiology. 2011;259:852-861.

89. BlueCross BlueShield of Tennessee Medical Policy Manual. Radioimmunoscintigraphy imaging (monoclonal antibody imaging) with Indium-111 capromab pendetide for prostate cancer. https://www.bcbst.com/mpmanual/Radioimmunoscintigraphy_ Imaging_Monoclonal_Antibody_Imaging_with_Indium-111_Capromab_Pendetide_ for_Prostate_Cancer_htm. Published November 10, 2007. Reviewed October 11, 2018. Accessed September 11, 2019.

90. BlueCross BlueShield of North Carolina. Corporate medical policy: monoclonal antibody imaging for prostate cancer. https://www.bluecrossnc.com/sites/ default/files/document/attachment/services/public/pdfs/medicalpolicy/monoclonal_ antibody_imaging_for_prostate_cancer.pdf. Published May 2011. Reviewed April 2018. Accessed September 11, 2019.

91. Aytu BioScience discounting PROSTASCINT ${ }^{\circledR}$ (Capromab Pendetide) Kit [letter]. April 2018. http://www.radiopharmaceuticals.info/uploads/7/6/8/7/76874929/ prostascint_discontinue_letter_april_2018_final.pdf. Accessed September 11, 2019. 
92. Afshar-Oromieh A, Babich JW, Kratochwil C, et al. The rise of PSMA ligands for diagnosis and therapy of prostate cancer. J Nucl Med. 2016;57:79S-89S.

93. Eiber M, Maurer T, Souvatzoglou M, et al. Evaluation of hybrid ${ }^{68} \mathrm{Ga}-\mathrm{PSMA}$ ligand PET/CT in 248 patients with biochemical recurrence after radical prostatectomy. J Nucl Med. 2015;56:668-674.

94. Hope TA, Goodman JZ, Allen IE, Calais J, Fendler WP, Carroll PR. Metaanalysis of ${ }^{68} \mathrm{Ga}$-PSMA-11 PET accuracy for the detection of prostate cancer validated by histopathology. J Nucl Med. 2019;60:786-793.

95. Perera M, Papa N, Christidis D, et al. Sensitivity, specificity, and predictors of positive ${ }^{68} \mathrm{Ga}$-prostate-specific membrane antigen positron emission tomography in advanced prostate cancer: a systematic review and meta-analysis. Eur Urol. 2016;70:926-937.

96. Morigi JJ, Stricker PD, van Leeuwen PJ, et al. Prospective comparison of ${ }^{18} \mathrm{~F}$ fluoromethylcholine versus ${ }^{68} \mathrm{Ga}$-PSMA PET/CT in prostate cancer patients who have rising PSA after curative treatment and are being considered for targeted therapy. J Nucl Med. 2015;56:1185-1190.

97. Afshar-Oromieh A, Zechmann CM, Malcher A, et al. Comparison of PET imaging with a ${ }^{68} \mathrm{Ga}$-labelled PSMA ligand and ${ }^{18} \mathrm{~F}$-choline-based PET/CT for the diagnosis of recurrent prostate cancer. Eur J Nucl Med Mol Imaging. 2014;41:11-20.

98. Calais J, Ceci F, Eiber M, et al. ${ }^{18}$ F-fluciclovine PET-CT and ${ }^{68} \mathrm{Ga}-\mathrm{PSMA}-11$ PET/CT in patients with early biochemical recurrence after prostatectomy: a prospective, single-centre, single-arm, comparative imaging trial. Lancet Oncol. 2019;9:12861294.

99. Lawhn-Heath C, Flavell RR, Behr SC, et al. Single-center prospective evaluation of ${ }^{68} \mathrm{Ga}$-PSMA-11 PET in biochemical recurrence of prostate cancer. AJR. 2019;213:266-274.

100. Fendler WP, Calais J, Eiber M, et al. Assessment of ${ }^{68}$ Ga-PSMA-11 PET accuracy in localizing recurrent prostate cancer: a prospective single-arm clinical trial. JAMA Oncol. 2019;5:856-863.
101. Wu SY, Boreta L, Shinohara K, et al. Impact of staging ${ }^{68} \mathrm{Ga}$-PSMA-11 PET scans on radiation treatment plans in patients with prostate cancer. Urology. 2019;125:154-162.

102. Calais J, Fendler WP, Eiber M, et al. Impact of ${ }^{68}$ Ga-PSMA-11 PET/CT on the management of prostate cancer patients with biochemical recurrence. $\mathrm{J} \mathrm{Nucl}$ Med. 2018;59:434-441.

103. Calais J, Czernin J, Cao M, et al. ${ }^{68} \mathrm{Ga}$-PSMA-11 PET/CT mapping of prostate cancer biochemical recurrence after radical prostatectomy in 270 patients with a PSA level of less than $1.0 \mathrm{ng} / \mathrm{mL}$ : impact on salvage radiotherapy planning. J Nucl Med. 2018;59:230-237.

104. Calais J, Czernin J, Fendler WP, Elashoff D, Nickols NG. Randomized prospective phase III trial of ${ }^{68} \mathrm{Ga}$-PSMA-11 PET/CT molecular imaging for prostate cancer salvage radiotherapy planning. BMC Cancer [PSMA-SRT]. 2019;19:18.

105. Sanchez-Crespo A. Comparison of gallium-68 and fluorine-18 imaging characteristics in positron emission tomography. Appl Radiat Isot. 2013;76:55-62.

106. Gorin MA, Pomper MG, Rowe SP. PSMA-targeted imaging of prostate cancer: the best is yet to come. BJU Int. 2016;117:715-716.

107. Giesel FL, Knorr K, Spohn F, et al. Detection efficacy of ${ }^{18}$ F-PSMA-1007 PET/ $\mathrm{CT}$ in 251 patients with biochemical recurrence of prostate cancer after radical prostatectomy. J Nucl Med. 2019;60:362-368.

108. Rowe SP, Campbell SP, Mana-Ay M, et al. Prospective evaluation of PSMAtargeted ${ }^{18} \mathrm{~F}-\mathrm{DCFPyL}$ PET/CT in men with biochemical failure after radical prostatectomy for prostate cancer. J Nucl Med. 2020;61:58-61.

109. Rousseau E, Wilson D, Lacroix-Poisson F, et al. A prospective study on ${ }^{18} \mathrm{~F}$ DCFPyL PSMA PET/CT imaging in biochemical recurrence of prostate cancer. J Nucl Med. 2019;60:1587-1593.

110. Vapiwala N, Hofman MS, Murphy DG, Williams S, Sweeney C. Strategies for evaluation of novel imaging in prostate cancer: putting the horse back before the cart. J Clin Oncol. 2019;37:765-769. 